\title{
Investigation of White Light Emission Observed During Damage in the Bulk of DKDP Crystals
}

C. W. Carr, H. B. Radousky, M. Staggs, A. Rubenchik, M. Feit, S. G. Demos

This article was submitted to Nonlinear Optics 2002, Wailea, Hawaii, July 29 - August 2, 2002 


\section{DISCLAIMER}

This document was prepared as an account of work sponsored by an agency of the United States Government. Neither the United States Government nor the University of California nor any of their employees, makes any warranty, express or implied, or assumes any legal liability or responsibility for the accuracy, completeness, or usefulness of any information, apparatus, product, or process disclosed, or represents that its use would not infringe privately owned rights. Reference herein to any specific commercial product, process, or service by trade name, trademark, manufacturer, or otherwise, does not necessarily constitute or imply its endorsement, recommendation, or favoring by the United States Government or the University of California. The views and opinions of authors expressed herein do not necessarily state or reflect those of the United States Government or the University of California, and shall not be used for advertising or product endorsement purposes.

This is a preprint of a paper intended for publication in a journal or proceedings. Since changes may be made before publication, this preprint is made available with the understanding that it will not be cited or reproduced without the permission of the author.

This report has been reproduced directly from the best available copy.

Available electronically at http://www.doc.gov/bridge

Available for a processing fee to U.S. Department of Energy

And its contractors in paper from

U.S. Department of Energy

Office of Scientific and Technical Information

P.O. Box 62

Oak Ridge, TN 37831-0062

Telephone: (865) 576-8401

Facsimile: (865) 576-5728

E-mail: reports@adonis.osti.gov

Available for the sale to the public from

U.S. Department of Commerce

National Technical Information Service

5285 Port Royal Road

Springfield, VA 22161

Telephone: (800) 553-6847

Facsimile: (703) 605-6900

E-mail: orders@ntis.fedworld.gov

Online ordering: http://www.ntis.gov/ordering.htm

OR

This work was performed under the auspices of the United States Department of Energy by the University of California, Lawrence Livermore National Laboratory under contract No. W-7405-Eng-48.

Technical Information Department's Digital Library

http://www.llnl.gov/tid/Library.html 


\title{
Investigation of White Light Emission Observed during Damage in the Bulk of DKDP Crystals
}

\author{
C.W. Carr*, H.B. Radousky* M.C. Staggs, A.M Rubenchik, M.D. Feit, S.G. Demos \\ Lawrence Livermore National Laboratory L-418 7000 East Avenue Livermore CA, 9455I, USA \\ *Also With University of California Davis, Physics Department, Davis CA, 95616, USA \\ carr19@llnl.gov
}

\begin{abstract}
We have investigated the flash of light that accompanies laser damage using time-resolved spectroscopy. Damage events were initiated in the bulk of DKDP and fused silica with 355-nm, 3-ns pulsed radiation. Spectra from the accompanying flash were recorded in the 200-500 nm wavelength range with 10 ns temporal resolution. Ten ns following damage initiation, the spectra were found to be roughly blackbody with temperatures on the order of $5000-7000 \mathrm{~K}$. The observed temperatures and cooling rates can be related to the size and electron density of the plasma "fireball" that initiates the damage event.

OCIS codes: (300.2140) Spectroscopy, Emission (140.3330) Laser damage
\end{abstract}

\section{Introduction}

The observed laser damage threshold in optical materials is significantly less than the theoretical intrinsic value. In fused silica, for 350-nm light, it has been estimated that the onset of avalanche breakdown should be on the order of $150 \mathrm{GW} / \mathrm{cm}^{2}[1]$. For the 3-ns pulses used in this study, this corresponds to $450 \mathrm{~J} / \mathrm{cm}^{2}$; which is 40 to 50 times the experimentally observed values. This discrepancy is generally attributed to the presence of defects, intrinsic or extrinsic, contained within nominally transparent materials $[2,3]$.

When laser damage occurs, plasma is formed at the sites of these defects and rapidly expands, absorbing large amounts of energy during the laser pulse $[4,5]$. The high energy density produces a micro-explosion, damaging the material. Shockwave propagation induces mechanical failure and material modification. This is followed on a slower time scale by melting and further material modification caused by temperature increase [6,7]. The white light emissions, which accompany these processes, contain crucial information concerning the mechanisms responsible for the damage. In this work, we report that the emission spectrum of fused silica is blackbody in nature as early as $10 \mathrm{~ns}$ after the termination of the laser pulse and that the ionized region can approach temperatures of $7000 \mathrm{~K}$.

\section{Experimental}

Fused silica $\left(\mathrm{SiO}_{2}\right)$ and DKDP Crystals samples at room temperature were irradiated with 355-nm 3-ns pulse radiation focused in the bulk of the materials with a spot determined by a knife-edge measurement to be approximately $30 \mu \mathrm{m}$ in size. The pump beam is brought in through a small turning mirror and focused by an offaxis parabolic mirror into the sample. A schematic representation of the apparatus may be seen in figure 1 . The short focal length of the mirror eliminated the possibility of surface damage and allowed the study of the bulk properties of the materials in question.

The same mirror collects the emission from the damage area with an f-number of unity. The collimated refection is transported by reflective optics to an $\mathrm{f}-4$ mirror and focused into a $200-\mu \mathrm{m}$ spectrometer slit. The $50-\mu \mathrm{m}$ collection region from this geometry closely matches the spot size of the damaging beam and thus reduces extraneous signal from sources such as bulk fluorescence. By using only reflective optics we prevent excessive loss in UV that would be experienced with refractive optics. The response of the system and absorption of the sample was determined by use of calibrated light sources. The data were reduced by removing background and instrument response. Commercial software was then used to fit the spectra to a modified Planckian distribution:

$$
I(\lambda)=C_{1}+C_{2} \lambda^{-5}\left(e^{0.144 / T \lambda}-1\right)^{-1}
$$

where $C_{1}, C_{2}$ and $T$ are fitting parameters. Fitting with a pure Planckian $\left(C_{1}=0\right)$ gives a slightly worse fit, but yields temperatures that differ by no more than $10 \%$. This discrepancy does not effect the conclusions of this work. 
A selection of data and the extracted temperatures are displayed in figures $2 \mathrm{a}$ and $2 \mathrm{~b}$. Additional fused silica data will be discussed in a future work [8].

A break in the data (individual points) can be seen from $325 \mathrm{~nm}$ to $425 \mathrm{~nm}$. This brake is due to a physical obstruction used to protect the ICCD from the laser line. A holographic filter would notch a much narrower band, but would transmit poorly in the UV.

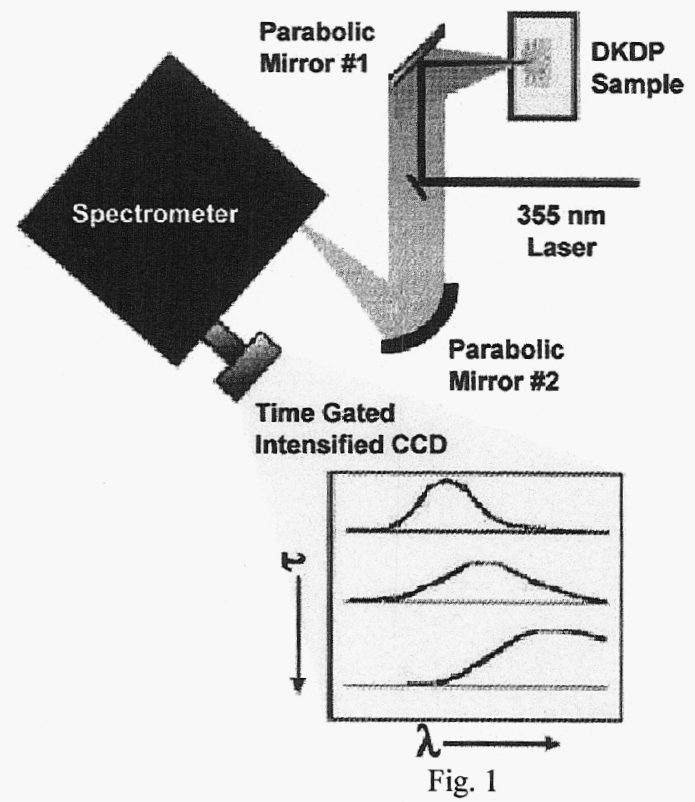

The $355 \mathrm{~nm}$ light is reflected off a small turning mirror and then focused by an off-axis parabolic mirror in to the bulk of the sample. After damage is initiated, the same mirror collects and re-collimates the light which then passes the turning mirror with about $10 \%$ loss. A second mirror focuses the light into a spectrometer coupled with a time gated intensified CCD.

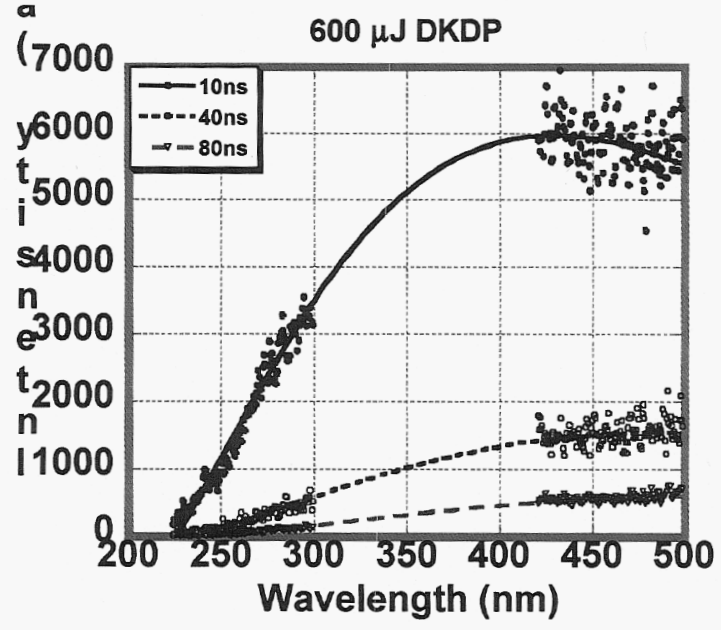

Fig. $2 \mathrm{a}$

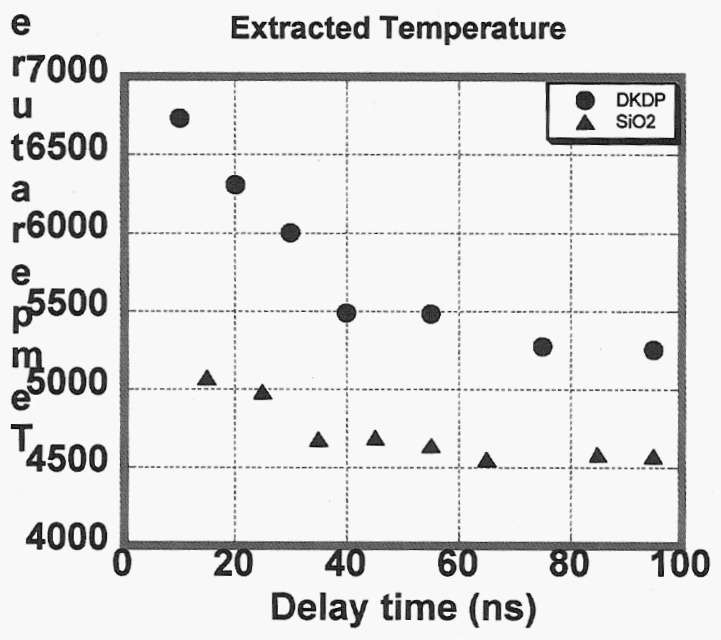

Fig. $2 b$

a)The individual points are the data collected from the ICCD from DKDP for 10, 40, and $80 \mathrm{~ns}$ after the laser pulse. The curves through the data are the fits generated by equation 1. Gaps in the spectra are the result of an obstruction blocking the laser line. b)Temperatures extracted form the fits of equitation 1 . Despite the uncertainty in the temperature $(\sim+/-200$

$\mathrm{K})$ the cooling of the ionized region can be seen as a function of delay time after the laser pulse has terminated. 


\section{Discussion}

In this work we have demonstrated that the emissions accompanying laser damage in fused silica and DKDP are blackbody in nature at times ranging from $10 \mathrm{~ns}$ to $100 \mathrm{~ns}$ after the laser pulse. The elevated temperatures observed indicate that a substantial amount of energy was absorbed from the laser fields. Because the surrounding material confines the plasma, its density must be essentially unchanged from the solid state. From the equation of state for fused silica, the pressure at the temperatures observed must be on the order of $150 \mathrm{kbars}$ [9]. This yields an energy density on the order of $10 \mathrm{~kJ} / \mathrm{cm}^{3}$. We can estimate from the cooling rate that the ionized region is on the order of $5 \mu \mathrm{m}$ in size [10].

For a fireball of $5 \mu \mathrm{m}$ in size the energy density corresponds to absorption of roughly $15 \mu \mathrm{J}$, or $\sim 2 \%$ of the laser pulse. This level of absorption can occur only if the electron density is on the order of the critical density $\left(10^{22}\right.$ $\mathrm{cm}^{-3}$ ) so that at least a small region is opaque to the laser radiation. The equilibrium electron density of $10^{17} \mathrm{~cm}^{-3}$ predicted by the Saha formula (electrons promoted across the band gap thermally) for the temperatures observed is several orders of magnitude too small for effective absorption to occur [4,9,11]. For this reason the electrons cannot be purely thermal in origin. The majority of free electrons must then be produced by impact ionization and electron avalanche.

\section{Conclusion}

Time resolved emission spectra observed during laser damage at time greater than $10 \mathrm{~ns}$ is found to be blackbody in nature. By fitting the emission spectra we are able to determine the temperature of the plasma fireball that produced the damage. The blackbody nature and high temperature of the ionized region indicates electron densities near or above the critical density are reached during laser irradiation and persist for tens of nanoseconds.

\section{Acknowledgement}

This work was performed under the auspices of the U. S. Department of Energy by the University of California, Lawrence Livermore National Laboratory under Contract No. W-7405-Eng-48.

\section{References}

1. A.M. Rubenchik, M.D. Feit, "Initiation, Growth and Mitigation of UV Damage in Fused Silica." Proceedings 2001 Annual Symposium on Optical Materials for High-Power Lasers, Boulder, Co.

2. N. Bloembergen, "Laser-Induced Electric Breakdown in Solids" IEEE Journal of Quantum Electronics, vol.QE-10, (no.3), pp.375-86, March 1974.

3. J. Glass and A. H. Guenther, "Laser induced damage of optical elem ents-a status report", Applied Optics 12, 637-649 (1973).

4. W.L. Kruer, "The physics of laser plasma interactions". Redwood City, Calif. : Addison-Wesley,. Series title: Frontiers in physics; vol. 73, c1988

5. S.G. Demos, M.R. Kozlowski, M. Staggs, L.L. Chase, A. Burnham, H. B. Radousky, "Mechanisms to explain damage growth in optical materials", Proceedings 2000 Annual Symposium on Optical Materials for High-Power Lasers, Boulder, Co p. 277

6. H. Jiang, J. McNary, H.W.K. Tom, M. Yan, H.B. Radousky, S.G. Demos. "Time-resolved studies of laser damage processes in DKDP crystals" Proceedings of the SPIE - The International Society for Optical Engineering, vol.3902, (Laser-Induced Damage in Optical Materials: 1999, Boulder, CO SPIE-Int. Soc. Opt, Eng, 2000, pp.294-301

7. R.W. Hopper, D.R. Uhlmann, "Mechanism of inclusion damage in laser glass", Journal of Applied Physics, vol.41, (no.10). pp.4023-37, Sept. 1970.

8. C.W. Carr, H.B. Radousky M.C. Staggs, A.M Rubenchik, M.D. Feit, S.G. Demos. "Time-Resolved spectroscopic investigation of emission observed during damage in the bulk of fused silica and DKDP crystals" Laser-Induced Damage in Optical Materials, Oct. 1-2, 2001 Boulder, $\mathrm{CO}$

9. "SESAME Report on the Los Alamos Equation of State Library", Report No. LALP83-4,T4 Group,LANL,Los Alamos,1983

10. Y.B. Zeldovich, Y.P Raizer, "Physics of shock waves and high-temperature hydrodynamic phenomena", New York, Academic Press, v.2, 1966-67.

11. F.F. Chen, "Introduction to plasma physics and controlled fusion", New York Plenum Press, c1984 